\title{
Development of a PCR Test for Rapid Diagnosis of Contagious Equine Metritis
}

\author{
Toru ANZAI, Masashi EGUCHI ${ }^{1)}$, Tsutomu SEKIZAKI ${ }^{1)}$, Masanobu KAMADA, Kohshi YAMAMOTO ${ }^{1)}$ and \\ Toshio OKUDA ${ }^{2)}$ \\ Epizootic Research Station, Equine Research Institute, Japan Racing Association, 1400-4 Shiba, Kokubunji-machi, Shimotsuga-gun, \\ Tochigi 329-0412, ${ }^{1}$ National Institute of Animal Health, 3-1-1 Kannondai, Tsukuba, Ibaraki 305-0856, and ${ }^{2}$ Hidaka Livestock Hygiene \\ Service Center, Kousei-cho, Shizunai-cho, Shizunai-gun, Hokkaido 056-0005, Japan
}

(Received 24 May 1999/Accepted 20 August 1999)

ABSTRACT. In order to establish a rapid diagnostic method for contagious equine metritis (CEM), we developed and evaluated a polymerase chain reaction (PCR) test. Species-specific PCR primer sets were derived from the DNA sequence of a cloned DNA fragment of Taylorella equigenitalis that did not hybridize with the genome of a taxomonically related species, Oligella urethralis. Single step PCR with primer set P1-N2 and two-step semi-nested PCR with primer sets P1-N2 and P2-N2 detected as low as 100 and 10 CFU of the bacteria, respectively. Single-step PCR detected T. equigenitalis from genital swabs of experimentally infected mares with sensitivity comparable to that of bacterial isolation. Furthermore, two-step PCR was more sensitive than the culture method. Upon examination of field samples, 12 out of 3,123 samples were positive by single-step PCR while only 2 were positive by bacterial culture. The 12 PCRpositive samples originated from 5 mares, of which 3 animals were considered to be carriers based on previous bacteriologic and serologic diagnoses for CEM. The PCR test described in this study would provide a specific and highly sensitive tool for the rapid diagnosis of CEM.—KEY WORDS: contagious equine metritis, equine, metritis, polymerase chain reaction, Taylorella equigenitalis.

J. Vet. Med. Sci. 61(12): 1287-1292, 1999

Contagious equine metritis (CEM) is a highly contagious, acute venereal disease of horses causing infertility and severely affecting breeding operations. Since the first reported outbreaks in 1977 in England [7] and Ireland [23], CEM has spread worldwide [15, 22] and remains a considerable economical problem among horse breeders in some countries including Europe [25] and Japan. The causative agent of CEM, Taylorella equigenitalis, is a gramnegative, nonmotile, coccoid rod which is classified in the family Pasteurellaceae and whose closest phylogenetic relative is Oligella urethralis $[2,4,5,16]$.

T. equigenitalis colonizes the surface of the endometrium of the uterus [24] causing endometritis and sterility in mares. The organism may then persist on the clitoris of mares to occasionally infect the penis of stallions that cover the mare [15]. Diagnosis of CEM is, therefore, performed by bacterial isolation from the cervix of uterus, the clitoral sinus, and the clitoral fossa of mares as well as the urethral orifice, the urethral sinus and the penile sheath of stallions [25]. However, because of microaerophilic and slowgrowing properties of $T$. equigenitalis, visible colony formation usually takes 4 to 6 days and is often obscured by growth of other bacteria contaminating the samples [15].

Rapid detection of $T$. equigenitalis using a polymerase chain reaction (PCR) based on the DNA sequence of the $16 \mathrm{~S}$ ribosomal RNA (rRNA) gene has already been developed to overcome the problems mentioned above [3, 13], and its effectiveness as a diagnostic method has been confirmed [6]. The PCR system based on the 16S rRNA gene usually provides high sensitivity because of multiple copies of the targeted sequence on the bacterial chromosome. However, many short DNA segments conserved among 16S rRNA genes may influence the specificity of this PCR test especially in the case of contamination by phylogenetically related bacteria. To overcome this problem, we designed original oligonucleotide primers and evaluated their use in PCR for the detection of T. equigenitalis in specimens from horses as a rapid and reliable method for diagnosis of CEM.

\section{MATERIALS AND METHODS}

Bacteria and culture conditions: Two strains of $T$. equigenitalis, Type strain (NCTC 11184) and Kentucky188 (K-188), as well as eighteen field isolates of $T$. equigenitalis collected in Japan from 1980 to 1990 were used in this report. Additionally, O. urethralis, Escherichia coli, Enterobacter aerogenes, Klebsiella pneumoniae subsp. pneumoniae, Pseudomonas aeruginosa, Pasteurella pneumotropica, Bordetella bronchiseptica, Streptococcus equi subsp. zooepidemicus, and Staphylococcus aureus subsp. aureus were used to evaluate the specificity of the PCR test. T. equigenitalis strains were cultured on Eugon chocolate agar [21] in an atmosphere of $10 \% \mathrm{CO}_{2}$ at $37^{\circ} \mathrm{C}$ for 2 days. Other bacteria were grown on Colombia agar (Difco Laboratories, U.S.A.) supplemented with 5\% heparinized horse blood at $37^{\circ} \mathrm{C}$ for $18 \mathrm{hr}$.

DNA preparation: Total DNAs of gram-negative bacteria were extracted by standard procedures [18]. For DNA isolation from gram-positive bacteria, the cells were first incubated in $10 \mathrm{mM}$ Tris- $\mathrm{HCl}(\mathrm{pH} \mathrm{8.0)}, 5 \mathrm{mM}$ EDTA supplemented with $5,000 \mathrm{U} / \mathrm{m} l$ of acromopeptidase (Wako Pure Chemical Industries, Ltd., Osaka, Japan) at $55^{\circ} \mathrm{C}$ for 30 min [9]. Plasmid DNAs were isolated using an alkaline lysis method [1].

DNA hybridization technique: Preparation of DNA 
probes, hybridization, and visualization of the hybridized DNA was done essentially as described previously [20].

Construction and screening of genomic library: A genomic library of T. equigenitalis $\mathrm{K}-188$ was constructed according to standard procedures [18]. Total DNA of $T$. equigenitalis K-188 was partially digested by Sau3AI and fractionated on sucrose density gradient. DNA fragments of 500 to $1000 \mathrm{bp}$ in size were ligated into BamHI-digested plasmid vector pUC119 with T4 DNA ligase. The ligated DNA molecules were then used to transform E. coli XL-1 blue (Stratagene, U.S.A.). Plasmid DNAs isolated from each clone were analyzed by dot blot and Southern hybridization with digoxigenin-labeled total DNA of $O$. urethralis. One clone, designated CEM-1, which hybridized with DNAs of all T. equigenitalis examined but not with those of other bacterial species was then selected for further analysis.

DNA sequencing: A 756-bp DNA sequence of clone CEM-1 was determined by dideoxy chain-termination method [19], and submitted to EMBL/GenBank/DDBJ databases under the accession number $\mathrm{AB} 011522$. A protein coding region was not detected in the sequence.

Preparation of templates for PCR test: DNA samples from cultured bacterial cells were prepared as described previously [14]. Cultures from genital samples were suspended in $1 \mathrm{~m} l$ of phosphate buffered saline, $\mathrm{pH}$ 7.0 (PBS) in $1.5 \mathrm{ml}$ Eppendorf tubes and centrifuged for $1 \mathrm{~min}$ at $15,000 \mathrm{rpm}$. Each pellet was then resuspended in $50 \mu \mathrm{l}$ of distilled water and boiled for $10 \mathrm{~min}$. Following centrifugation for $3 \mathrm{~min}$ at 15,000 rpm, the supernatant was subsequently used as template for PCR.

PCR primers and conditions: Two forward ( $\mathrm{P} 1$ and $\mathrm{P} 2)$ and two reverse (N1 and N2) primers were designed from the sequence determined in this study using computer software package RightPrimer M1.2.3. (BioDisk Software, U.S.A.). Primers synthesized were as follows: P1, 5'CCATTAGAGGCTGTTAATCAATCGGGAAACC-3' (positions 38 to 67 of the 756-bp sequence); P2, 5'CCATACCGAACCCAATACCAAGCACACAAG-3' (245 to 274); N1, 5'-TCGGTGGAGCTGAGAAACGTGAGT ATGATG-3' (746 to 717); N2, 5'-GTGTCATTAAGGT GTGTATTTGGTCTGGTG-3' (482 to 453). PCR was performed in a $100 \mu l$ volume containing $10 \mu l$ of template DNA, $10 \mathrm{mM}$ Tris-HCl (pH 9.0), $50 \mathrm{mM} \mathrm{KCl}, 1.5 \mathrm{mM}$ $\mathrm{MgCl}_{2}, 0.1 \%$ Triton X-100, $0.2 \mathrm{mM}$ (each) deoxynucleoside triphosphates, $0.4 \mu \mathrm{M}$ of each primer, and $2.5 \mathrm{U}$ of Taq DNA polymerase (Perkin-Elmer, ABI, U.S.A.). Samples were amplified by one denaturation step at $95^{\circ} \mathrm{C}$ for $3 \mathrm{~min}$ followed by 35 cycles consisting of denaturation at $95^{\circ} \mathrm{C}$ for $30 \mathrm{sec}$, annealing at $58^{\circ} \mathrm{C}$ for $30 \mathrm{sec}$, and extension at $72^{\circ} \mathrm{C}$ for $30 \mathrm{sec}$, with a final incubation at $72^{\circ} \mathrm{C}$ for $10 \mathrm{~min}$ using a zymoreacter II AB-1820 (ATTO Co., Ltd., Tokyo, Japan) thermocycler. For the two-step PCR, the resultant PCR products were further amplified by a second pair of primers (P2-N2) using the same reaction conditions as described above except that the amplification was repeated for 25 cycles with an annealing temperature of $62^{\circ} \mathrm{C}$.
Amplicons were analyzed by $2 \%$ agarose gel electrophoresis.

Experimental infection: Two Thoroughbred mares were administered dinoprost (Fuji Chemical Industries, Ltd., Toyama, Japan) and estradiol (Sankyo Co., Ltd., Tokyo, Japan) intramuscularly for four days as follows: Day 1, 6 $\mathrm{mg}$ of dinoprost; Day 2, $6 \mathrm{mg}$ of dinoprost; Day 3, $5 \mathrm{mg}$ of estradiol; Day 4, $5 \mathrm{mg}$ of estradiol. On day 5, approximately $10^{9}$ colony forming units (CFU) of T. equigenitalis K-188 were suspended in PBS and inoculated into the uterus with the aid of a catheter. Swabs were collected from the cervix of the uterus and the clitoral fossa by using a bacterial collection and transportation system (CULTURETTE, BBL, U.S.A.) every 1-3 weeks until 23 weeks post inoculation (PI). Isolation and identification of bacteria was carried out as described previously [10].

Field samples: Swabs of the cervix of the uterus, the clitoral fossa and the clitoral sinus of Thoroughbred mares, the urethral orifice, the urethral sinus and the penile sheath of Thoroughbred stallions were collected at horse-breeding farms in Hokkaido, Japan. Collection swabs used were CULTURETTE, MINI-TIP CULTURETTE (BBL), TRANSWAB (Medical Wire \& Equipment Co., Ltd., Wilts., U.K.), and TRANSWAB E.N.T.(Medical Wire \& Equipment Co., Ltd.).

\section{RESULTS}

Optimization of primer sets for PCR test: DNA fragments of 445-bp and 238-bp were amplified from total DNA of $T$. equigenitalis $\mathrm{K}-188$ using the primer sets $\mathrm{P} 1-\mathrm{N} 2$ and $\mathrm{P} 2-$ $\mathrm{N} 2$, respectively. However, amplification of specific DNA fragments was not successful using either of the primer sets P1-N1 or P2-N1 (Fig. 1).

Specificity and sensitivity of the PCR test: The specificities of selected PCR primers were tested against total DNAs of $20 \mathrm{~T}$. equigenitalis strains and 9 other bacterial species listed in Materials and Methods. Primer set P1-N2 amplified a 445-bp DNA fragment from all $T$. equigenitalis tested (a part of the results is shown in Fig. 2) while DNA of other bacterial species was not amplified (Fig. 2). These results confirmed the specificity of the PCR amplification. Similarly, the specificity of the second primer set, P2-N2, which amplified a DNA segment of 234 bp was also confirmed (data not shown).

Using 10-fold serial dilutions of T. equigenitalis culture grown to log phase, single-step PCR with primer set P1-N2 and two-step PCR with primer sets P1-N2 and P2-N2 were shown to detect bacterial numbers as low as 100 and 10 CFU, respectively.

PCR detection from experimentally infected horses: Genital swabs collected from the cervix of the uterus and the clitoral fossa of two mares experimentally infected with T. equigenitalis were subjected to bacterial isolation and PCR analysis (Table 1). T. equigenitalis was recovered from the cervix of the uterus from 1 to 11 weeks postinoculation (PI) in horse A, and from 1 to 7 weeks PI in 
horse B. T. equigenitalis was detected during the same period in both horses by single-step and two-step PCR. From the clitoral fossa, T. equigenitalis was consistently isolated throughout the duration of the experiment in horse A, and for all test periods except weeks 1, 11 and 14 PI in horse B. T. equigenitalis was detected from the clitoral

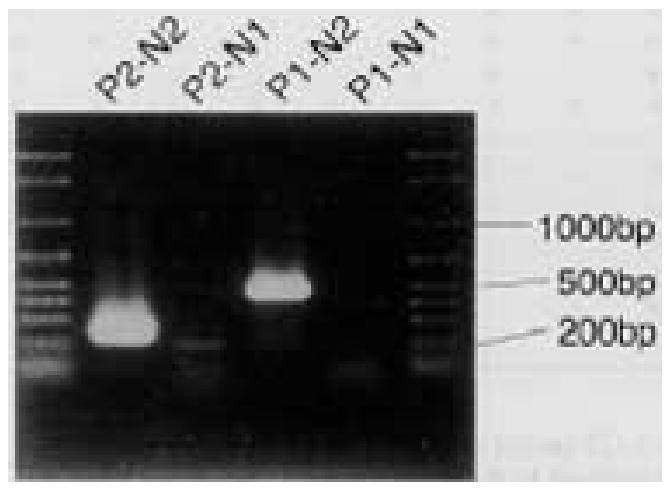

Fig. 1. PCR amplification of DNA sequences from total DNA of Taylorella equigenitalis K-188 strain using four combinations of the primers. The PCR products were analyzed on $2 \%$ agarose gel electrophoresis. Primer sets are indicated above the lanes. P1(position: 38-67 (+))-N2 (position:482453(-)) primer set amplify a 445-bp DNA fragment and P2 (position: 245-274 (+))-N2 primer set amplify a 238-bp DNA fragment. Numbers on the right indicate sizes (in base pairs) of DNA marker. fossa of horse A by single-step PCR at all test periods except weeks 9 and 14 PI, and was consistently detected by twostep PCR through the duration of the experiment. Detection of T. equigenitalis from swabs of the clitoral fossa of horse B by single-step PCR was less consistent, as positive results were obtained from samples of 1 to 7 and 16, 18 and 23 weeks PI. Although two-step PCR was much more successful in detecting T. equigenitalis in swabs of the clitoral fossa of horse B, samples of weeks 11 and 14 PI remained negative.

Application for field samples: A total of 3,123 genital swabs collected from 1,865 mares and 38 stallions were subjected to a conventional bacterial isolation method and single-step PCR. Results obtained are summarized in Table 2. Single-step PCR could detect $T$. equigenitalis from not only 2 samples that were positive by bacterial culture but also from 10 samples that were negative by bacterial culture, suggesting that the PCR test was more sensitive than bacterial isolation from field samples. The 10 bacterial culture negative PCR-positive samples were collected from 5 mares, of which two were positive by bacterial culture and one was positive by serologic examination [8] performed two years prior. Nevertheless, two of the PCRpositive mares appeared to be negative by previous bacteriologic and serologic analyses. These results suggest that PCR may be more effective in detecting carrier animals with chronic infection. However, among the PCR-positive samples, some amplified products showed a faint band of 445 bp upon agarose gel electrophoresis. All samples were subsequently subjected to a second semi-nested PCR

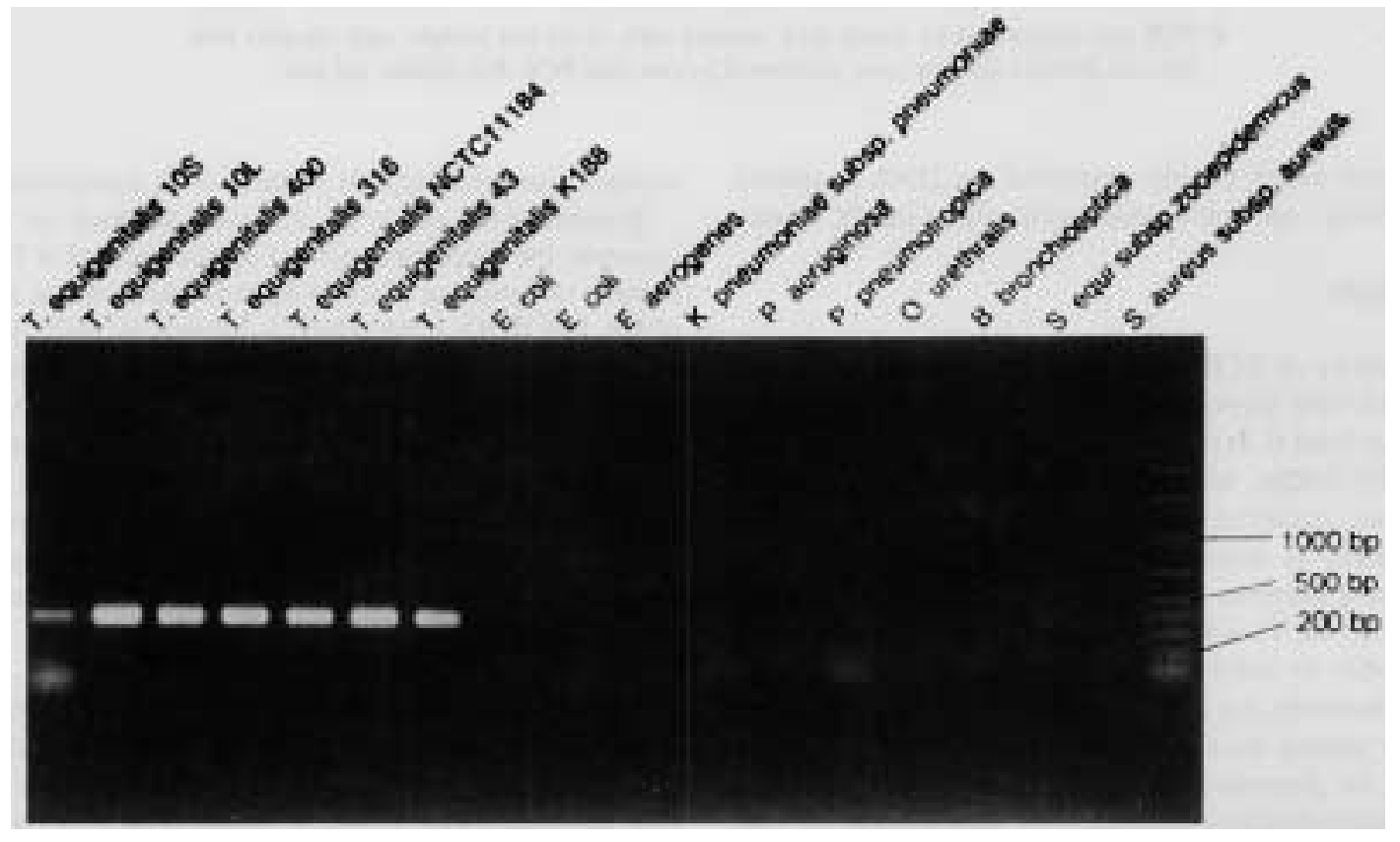

Fig. 2. PCR amplification of a DNA sequence from total DNAs of Taylorella equigenitalis field isolates and other bacterial species. The single-step PCR products with primer set P1-N2 were analyzed on $2 \%$ agarose gel electrophoresis. The bacteria used are indicated above the lanes. Numbers on the right indicate sizes (in base pairs) of DNA marker. 
Table 1. Detection of Taylorella equigenitalis from genital swabs collected from two Thoroughbred mares experimentally inoculated with strain K-188

\begin{tabular}{|c|c|c|c|c|c|c|c|c|c|c|c|c|c|c|}
\hline \multirow{2}{*}{ Horse } & \multirow{2}{*}{ Genital site } & \multirow{2}{*}{ Method of detection } & \multicolumn{11}{|c|}{ Weeks postinoculation } & \multirow[b]{2}{*}{23} \\
\hline & & & 1 & 3 & 5 & 7 & 9 & 11 & 12 & 14 & 16 & 18 & 20 & \\
\hline A & Cervix of uterus & Bacterial isolation & + & + & + & + & + & + & - & - & - & - & - & - \\
\hline A & Cervix of uterus & Single-step PCR & + & + & + & + & + & + & - & - & - & - & - & - \\
\hline A & Cervix of uterus & Two-step PCR & + & + & + & + & + & + & - & - & - & - & - & - \\
\hline A & Clitoral fossa & Bacterial isolation & + & + & + & + & + & + & + & + & + & + & + & + \\
\hline A & Clitoral fossa & Single-step PCR & + & + & + & + & - & + & + & - & + & + & + & + \\
\hline A & Clitoral fossa & Two-step PCR & + & + & + & + & + & + & + & + & + & + & + & + \\
\hline $\mathrm{B}$ & Cervix of uterus & Bacterial isolation & + & + & + & + & - & - & - & - & - & - & - & - \\
\hline B & Cervix of uterus & Single-step PCR & + & + & + & + & - & - & - & - & - & - & - & - \\
\hline B & Cervix of uterus & Two-step PCR & + & + & + & + & - & - & - & - & - & - & - & - \\
\hline B & Clitoral fossa & Bacterial isolation & - & + & + & + & + & - & + & - & + & + & + & + \\
\hline B & Clitoral fossa & Single-step PCR & + & + & + & + & - & - & - & - & + & + & - & + \\
\hline B & Clitoral fossa & Two-step PCR & + & + & + & + & + & - & + & - & + & + & + & + \\
\hline
\end{tabular}

Table 2. Detection of Taylorella equigenitalis from 3,123 genital swabs collected from 1,865 Thoroughbred mares and 38 Thoroughbred stallions in the Hidaka district, the main racehorse-breeding area in Japan

\begin{tabular}{lccc}
\hline & & \multicolumn{2}{c}{ No. of positive samples } \\
\cline { 3 - 4 } Genital site & No. of test samples & Bacterial isolation & PCR $^{\text {a) }}$ \\
\hline Cervix of uterus & 1,721 & 0 & 3 \\
Clitoral fossa & 631 & 0 & 4 \\
Clitoral sinus & 668 & 2 & 5 \\
Urethral orifice, urethral & 103 & 0 & 0 \\
$\quad$ sinus, and penile sheath & & & \\
\hline Total & 3,123 & 2 & 12 \\
\hline
\end{tabular}

a) PCR was performed by single-step method with all of test sample, and samples that showed positive reaction were confirmed by two-step PCR. For details, see text.

amplification which clearly amplified the DNA fragment PCR of $234 \mathrm{bp}$, confirming the specificity of the PCR test.

\section{DISCUSSION}

The rapidity of PCR analysis is a great benefit in the diagnosis of slow growing bacterial infections. In the case of CEM, at least 6 days are usually required for the final diagnosis by culture, while PCR test requires only one day. Furthermore, bacterial isolation from specimens such as genital swabs is usually hampered by the growth of contaminating bacteria. Eugon chocolate agar medium used for isolation of $T$. equigenitalis is supplemented with streptomycin to inhibit overgrowth of contaminating bacteria. However, the incidence of streptomycin-resistance is not rare among bacterial isolates from horse genitalia. Moreover, the presence of atypical T. equigenitalis isolates showing streptomycin-sensitivity [12], slow-growth [21] or unusual colony morphology phenotypes $[11,17]$ make detection of $T$. equigenitalis difficult by bacterial culture. A PCR test can be applied for the detection of $T$. equigenitalis in spite of the presence of drug resistant contaminants and atypical variants of $T$. equigenitalis.

Bleumink-Pluym et al. [3] and Miserez et al. [13] reported the development and application of a PCR test capable of detecting 10 to 15 bacteria based on the sequence of the 16S rRNA gene which is present in multiple copies on the bacterial genome. According to the results of sensitivity tests using pure culture of T. equigenitalis, our single-step PCR test may be somewhat less sensitive than the above PCR test, although a direct comparison was not done. Nevertheless, the apparent differences in sensitivity were likely due to the presence of only a single copy of our target sequence per genome, compared to multiple copies of the $16 \mathrm{~S}$ rRNA gene.

In order to increase the sensitivity of the PCR test, we designed an outer primer set $(\mathrm{P} 1-\mathrm{N} 1)$ for initial PCR amplification and an inner primer set (P2-N2) for subsequent nested PCR amplification. However, for unknown reasons, PCR reactions using primer N1 failed to amplify the desired DNA fragment despite employing computer analysis in its design. Also, other primers designed in a similar fashion slightly upstream from N1 could not amplify template DNA (data not shown). Therefore, primer set P1-N2 was 
employed for first amplification and $\mathrm{P} 2-\mathrm{N} 2$ primer set was used for secondary semi-nested PCR amplification.

We designed long primers of high $\mathrm{G}+\mathrm{C}$ content to allow PCR amplification at a high annealing temperature to increase specificity of the test. Sensitivity of our single-step PCR test was satisfactory for field diagnosis as shown in Table 2. Although two-step PCR appeared to be more sensitive than single-step PCR or a previously described PCR test targeting the 16S rRNA gene sequence, two-step PCR is more costly and complex to perform. Therefore, single-step PCR in combination with a semi-nested amplification using primers described here is a suitable method for practical analysis of a large number of field specimens. Furthermore, two-step PCR is a highly powerful tool for detection of low bacterial numbers colonizing the clitoral site of carrier horses.

During comparative study using samples collected from the clitoral fossa of experimentally infected horses (Table 1), two samples were shown to be negative by all three tests. Taking into account these results, the number of bacteria in the clitoral fossa may fluctuate during the course of infection. These results suggest the importance of repeated examinations for improving the reliability of diagnosis as has been repeatedly insisted upon previously $[15,25]$.

PCR is an effective tool for detection of T. equigenitalis. However, occasional contamination by smegma and charcoal in the specimens may inhibit PCR amplification even though bacterial growth would not be affected. Therefore, it is advisable that swabs should be carefully collected from genital sites to avoid a contamination of excessive amounts of smegma and should be transported in a medium without charcoal.

ACKNOWLEDGMENTS. We are grateful to Dr. J. T. Bryans, University of Kentucky for supplying the $T$. equigenitalis K-188 strain. We thank Ms. F. Yomogida and Ms. J. Goma for their technical assistance.

\section{REFERENCES}

1. Birnboim, H. C. and Doly, J. 1979. A rapid alkaline extraction procedure for screening recombinant plasmid DNA. Nucleic Acids Res. 7: 1513-1523.

2. Bleumink-Pluym, N.E.A. ter Laak and van der Zeijst, B.A.M. 1990. Epidemiologic study of Taylorella equigenitalis strains by field inversion gel electrophoresis of genomic restriction endonuclease fragments. J. Clin. Microbiol. 28: 2012-2016.

3. Bleumink-Pluym, N. M. C., Werdler, M. E. B., Houwers, D. J., Parlevliet, J. M., Colenbrander, B. and Van der Zeijst, B. A. M. 1994. Development and evaluation of PCR test for detection Taylorella equigenitalis. J. Clin. Microbiol. 32: 893896.

4. B $\emptyset$ vre, K. and Hagen, N. 1981. The family Neisseriaceae: rod-shaped species of the genera Moraxella, Acinetobacter, Kingella, and the Branhamella group of cocci, pp. 15061529. In: The Prokaryotes ( Starr, M.P., Stolp, H., Truper, H.G., Balow, A. and Schlegel, H.G. eds.), Springer-Verlag, Berlin.
5. Bøvre, K. 1979. Proposal to divide the genus Moraxella Lwoff 1939 emend. Henriksen and Bvre 1968 into two subgenera, subgenus Moraxella (Lwoff 1939) Bovre 1979 and subgenus Branhamella (Catlin 1970) Bovre 1979. Int. J. Syst. Bacteriol. 29: 403-406.

6. Chanter N., Vigano, F., Collon, N. C. and Mumford, J. A. 1998. Use of a PCR assay for Taylorella equigenitalis applied to samples from the United Kingdom. Vet. Rec. 22: 225-227.

7. Crowhurst, R. C. 1977. Genital infection in mares. Vet. Rec. 100: 476.

8. Eguchi, M., Kuniyasu, C. and Kishima, M. 1988. Passive hemagglutination test for detection of antibodies against Taylorella (Haemophilus) equigenitalis in sera of mares. Vet. Microbiol. 18: 155-161.

9. Ezaki, T. and Suzuki, S. 1982. Achromopeptidase for lysis of anaerobic gram-positive cocci. J. Clin. Microbiol. 16: 844846.

10. Kamada, M., Akiyama, Y., Oda, T. and Fukuzawa, Y. 1981. Contagious equine metritis: Isolation of Haemophilus equigenitalis from horses with endometritis in Japan. Jpn. J. Vet. Sci. 43: 565-568.

11. Kamada, M., Anzai, T., Kanemaru, T., Wada, R. and Kumanomido, T. 1987. Contagious equine metritis: Characterization of small and large colonial variants of Taylorella equigenitalis isolated from a laboratory strain. Bull. Equine Res. Inst. 24: 23-32.

12. Kamada, M., Kumanomido, T., Anzai, T., Kanemaru, T., Senba, H. and Ohishi, H. 1986. Isolation and drug susceptibility of streptomycin sensitive Taylorella equigenitalis from mares with metritis and infertility in Japan. Bull. Equine Res. Inst. 23: 55-61.

13. Miserez, R., Frey, J., Krawinkeler, M. and Nicolet, J. 1996. Identification and diagnosis of Taylorella equigenitalis by a method of DNA-amplification (PCR). Schweiz. Arch. Tierheilk. 138: 115-120.

14. Osaki, M., Sato, Y., Tomura, H., Ito, H. and Sekizaki, T. 1997. Genetic diversity of the genes encoding the outer membrane lipoprotein (omlA) of Actinobacillus pleuropneumoniae. J. Vet. Med. Sci. 59: 213-215.

15. Powell, D. G. 1981. Contagious equine metritis. Adv. Vet. Sci. Comp. 25: 161-184.

16. Rossau, R., Kersters, K., Falsen, E., Jantzen, E., Segers, P. Union, A., Nehls, L. and De Ley, J. 1987. Oligella, a new genus including Oligella urethralis comb. nov. (formerly Moraxella urethralis) and Oligella ureolytica sp. nov. (formerly CDC group IVe): relationship to Taylorella equigenitalis and related taxa. Int. J. Syst. Bacteriol. 37: 198-210.

17. Sahu, S. P., Wool, S. and Breese, S. S. Jr. 1982. Observation on the morphology of contagious equine metritis bacterial colonies isolated from infected pony mares. Am. J. Vet. Res. 43: 796-800.

18. Sambrook, J., Fritsch E.F. and Maniatis, T. 1989. Molecular Cloning: a Laboratory Manual. Cold Spring Harbor Laboratory, Cold Spring Harbor, N.Y.

19. Sanger, F., Nicklen, S. and Coulsen, A. R. 1977. DNA sequencing with chain-terminating inhibitors. Proc. Natl. Acad. Sci. U.S.A. 74: 5463-5467.

20. Sekizaki, T., Ito, H., Asawa, T. and Nonomura, I. 1993. DNA sequence of type 1 fimbirn, Fpul1, gene from a chicken pathogenic Escherichia coli serotype 078. J. Vet. Med. Sci. 55: 395-400.

21. Swaney, L. M. and Sau, S. P. 1978. CEM: Bacteriological 
methods. Vet. Rec. 102: 43.

22. Swerczek, T. W. 1978. Contagious equine metritis in the USA. Vet. Rec. 102: 512-513.

23. Timoney, P. J., Ward, J. and Kelly, P. 1977. A contagious genital infection of mares. Vet. Rec. 101: 103.

24. Wada, R., Kamada, M., Fukunaga, Y. and Kumanomido, T.
1983. Studies on contagious equine metritis IV. Pathology in horses experimentally infected with Haemophilus equigenitalis. Bull. Equine Res. Inst. 20: 133-143.

25. Watson, E. D. 1997. Swabbing protocols in screening for contagious equine metritis. Vet. Rec. 140: 268-271. 